\title{
Nos fios de Ariádne: cartografia da relação saúde- trabalho numa escola pública de Vitória-ES ${ }^{*}$
}

\author{
Marinete Rosa Pereira Mascarello
}

Faculdade Salesiana de Vitória e Universidade Federal do Espírito Santo,

Núcleo de Atenção à Saúde do Trabalhador do Hospital Universitário Cassiano Antônio de Morais

\section{Maria Elizabeth Barros de Barros}

Universidade Federal do Espírito Santo, Departamento de Psicologia e Programa de Pós-Graduação em Educação

Este artigo é resultado de uma pesquisa sobre a organização do trabalho e a produção de saúde/doença dos professores de uma escola da rede pública es-

* O título busca estabelecer uma analogia entre a escola pesquisada e o labirinto do Minotauro, da mitologia grega, por conta de sua arquitetura e do seu modo de funcionamento, absolutamente imprevisível a cada virar de esquina. Na mitologia

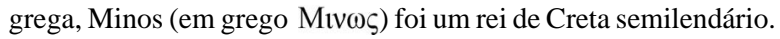
Ariádne ou Ariane é a filha de Minos, que se apaixonou por Teseu, herói que decidiu livrar Atenas do pesado tributo devido a Creta e, com esse objetivo, foi mandado a essa cidade como sacrifício ao Minotauro que habitava um labirinto construído por Dédalo. O labirinto foi tão bem projetado que quem se aventurasse por ele não conseguiria mais sair e era devorado pelo Minotauro. Ariádne, a fim de ajudar o amado a enfrentar o Minotauro, deu a ele uma espada e um novelo de fios de lã para marcar o caminho de volta. Assim, Teseu conseguiu matar o monstro e salvar-se com os companheiros. A expressão "nos fios de Ariádne" é utilizada, portanto, no sentido de seguir, perseguir, acompanhar acontecimentos, e está em consonância com a metodologia utilizada na pesquisa. tadual ${ }^{1}$ localizada na cidade de Vitória, capital do estado do Espírito Santo. A pergunta que direcionou o processo investigativo foi: "nós, trabalhadores da educação, estamos preparados para encarar os desafios colocados pelos modos de trabalho nas escolas?”. A direção que buscamos afirmar para as práticas no campo da educação pretende dar a conhecer a complexidade da vida psicossocial, considerando que ela é forjada no seio de uma rede de elementos heterogêneos, entre os quais se incluem os processos de trabalho.

Buscamos focar as transformações que se processam nos sujeitos e no mundo, orientando nosso olhar para a seguinte indagação: "como se está operando a produção dessas conexões?" (Athayde, 1999, p. 195). Tal direcionamento do olhar implica que façamos, de imediato, uma torção em nossa abordagem, que não deverá focar o "sujeito humano", "o traba-

${ }^{1}$ As escolas estaduais construídas na década de 1970, em conseqüência de acordos assinados entre os governos brasileiro e norte-americano, são conhecidas como escolas polivalentes. Ao longo do texto o leitor encontrará mais informações sobre elas. 
lhador", mas o processo de trabalho que se encontra em curso, processo este que, longe de ser considerado natural, é tomado como efeito concreto de um modo de produzir, distribuir e consumir os meios de vida num dado momento histórico. "Interessa-nos, neste enfoque, algo que se passa na ordem do impessoal e do comum e que pode ser considerado como um plano de composição a partir do qual se engendram tanto as formas históricas de produção como os próprios sujeitos que lhes concernem" (Barros \& Fonseca, 2004, p. 134). Nosso lócus de análise, portanto, é esse ponto de encontro sujeito (trabalhador/docente) e objeto (trabalho pedagógico), colocado em relação de intercessão e de interferência de um sobre o outro, não podendo ser pensados fora dessa relação (idem).

Nesse sentido, o saber pedagógico demanda aproximação com saberes que viabilizem essa direção de análise. Com esse objetivo, buscamos fazer intercessão com a ergologia e a psicodinâmica do trabalho, de forma que se estabeleça uma relação "entre" esses saberes e a pedagogia, um cruzamento como ponto de interferência (Deleuze, 1992) para viabilizar a análise na direção que estamos apontando.

Nesse contexto conceitual e metodológico, a organização do trabalho é compreendida como uma construção histórica, ou seja, indica a forma como os humanos se organizam para produzir bens materiais, a própria vida, a si mesmos. Em cada contexto histórico há uma forma específica de organizar o trabalho. Trata-se, então, de um conceito que utilizamos para fazer referência às formas como os docentes e demais atores se organizam no encaminhamento de suas tarefas para atingir os objetivos definidos na escola. Conforme Dejours, Abdoucheli e Jayet (1994), a organização do trabalho fala, portanto, da divisão do trabalho que se efetiva pela repartição das tarefas de acordo com as competências dos diversos sujeitos que compõem um grupo de trabalho; do parcelamento dos tempos e o ritmo de execução das atividades; das pausas, ou seja, de todos os modos operatórios prescritos e efetivados presentes na situação de trabalho. E, no âmbito das práticas escolares, isso se expressa, por exemplo, no fato:
[...] de a aula não ser mais de cinqüenta minutos. Quando as aulas passaram a ser de uma hora e que eu só ficava na sala de aula, não tinha condições de ir ao banheiro, de beber uma água. Era só sala de aula, sala de aula. Você só ia pra escola pra dar aulas. Você não tinha planejamento, aquele período de descanso, não. (Professora A)

Ao conceituar a organização do trabalho, Dejours, Abdoucheli e Jayet (1994) incluem também a divisão de homens e mulheres, constituindo as relações hierárquicas que sinalizam para a repartição das responsabilidades, de controle e de comando que apontam a dimensão do exercício de poder instituído; as relações com os companheiros de trabalho que indicam o contexto social em que essas relações são materializadas, podendo ser geradoras de saúde ou doença, e também se expressar em sobrecarga de trabalho para alguns.

Dessa forma, com o propósito de conhecer o trabalho que professores e professoras desenvolvem e os efeitos na produção de sujeitos, de saúde e de doença desses trabalhadores, elegemos a cartografia como método, visto que nos permitiria acompanhar os docentes fazendo história em seu trabalho concreto. Desse termo, emprestado dos geógrafos, apropriaram-se Deleuze e Guattari (1996) para designar a ação de acompanhar os acontecimentos na constituição do mundo.

O método cartográfico é aquele que, como qualquer outro, fala de uma direção ou de um caminho a ser percorrido e que nos coloca engajados com o concreto. No entanto, seu caráter é circunstancial, na medida em que nos possibilita visualizar "os pontos de congelamento da capacidade normativa, os limites que urgem a experimentação, a intervenção que desestabiliza e articula fragmentos para a criação de novos territórios existenciais" (Passos \& Benevides, 2003, p. 2). Nesse sentido, a cartografia não permite separar descrição de funcionalidade, ou seja, no momento em que descrevemos um fato, nós o colocamos a funcionar. A descrição de um fato não se realiza separando o sujeito que descreve e aquilo que por ele é descrito.

Tal processo assemelha-se ao de seguir os "fios 
de Ariádne", já que permite que nos movimentemos junto com as transformações que vão acontecendo no real. Permite-nos seguir os "fios" do trabalho real e os "usos de si pelo si e pelos outros", sendo colocados em ato pelos professores no cotidiano do labirinto-escola. Nas palavras de Schwartz (1992, p. 19), o "uso de si por si traz a marca do que é para o homem a herança da vida dele". Trata-se de uma retroação do humano sobre o ser vivo a partir de uma concepção mesmo da vida, que os estudos sobre a atividade no trabalho nos conduzem a considerar que

[...] as modalidades de uso de si remetem certamente também aos destinos individuais, às negociações, por sua vez particulares, entre a cena coletiva e o que a história produziu em cada um de nós como marcas "particulares". Do ser vivo ao ponto de vista privado, permanece-se no individual, do ser vivo aos atos de trabalho, permanece-se na dinâmica da atividade, do trabalho ao privado, na história e o simbolismo. (Schwartz, 1992, p. 20)

Ao cartografar o fazer cotidiano dos docentes, buscávamos dar visibilidade a uma luta pela saúde que já está acontecendo na escola, o que não significa que, em termos de quantidade ou qualidade, seja o suficiente para a promoção de saúde. Entretanto, podemos estar cegos e surdos para essas lutas em curso. Percebê-las é difícil, pois elas acontecem meio camufladas. A cartografia, ao diferenciar-se do mapa que institui contornos, recorta, isola e elege o que reproduzir, e assim pode ajudar-nos a "detectar" essas lutas, a dar-lhes visibilidade.

Com o objetivo de compreender e acompanhar a reconfiguração do meio de trabalho, utilizamos a vivência institucional e as entrevistas semi-estruturadas como estratégias metodológicas. Foram realizadas quatro entrevistas: duas com professores (contratados) e duas com professoras (concursadas), sendo uma delas gravada com uma professora afastada por licença médica. A escolha dos sujeitos foi em função da abertura e disponibilidade desses professores e dessas professoras para participarem da pesquisa. Todas as vivências na escola foram relatadas num diá- rio de campo, que contém as entrevistas e nossas impressões sobre as situações que experimentávamos. As entrevistas com os docentes e as conversas informais com os demais sujeitos da escola foram gravadas, totalizando 35 horas, e abordavam as temáticas de saúde, doença, trabalho, relações intersubjetivas com os pares e alunos, condições de trabalho, vínculo empregatício etc. Procuramos ainda participar de algumas reuniões da escola, como conselhos de classe, planejamento de festas e discussões sobre calendário de provas. Acompanhamos festas, comemorações, exibição de teatro, de coral. Conhecemos o trabalho de merendeiras, serventes e porteiros.

A escola pesquisada é denominada "labirinto", numa analogia à lenda grega do Minotauro e sua morada. A idéia da metáfora surgiu durante o estudo de campo, quando acompanhávamos uma aula de história. Achamos que fazia sentido, não apenas pelo funcionamento absolutamente imprevisível da escola, mas também pelas características da construção, formada por enormes corredores, nos quais inicialmente nos perdíamos. Embora o Minotauro seja descrito na lenda como um monstro, uma aberração da natureza instituída como castigo ao rei Minos, que ousou desobedecer ao poder dos deuses (Brandão, 1991), aqui ele é entendido como um ser múltiplo, híbrido, que está constantemente se permitindo explorar novas normas e formas de vida, subvertendo as linearidades e a repetição no meio de trabalho. O labirinto costuma ser visto como lugar de confusão, de erros, mas aqui é adotado como metáfora da complexidade, lugar das dobras, do inesperado, do múltiplo. Também é visto como lugar das incertezas, pois a cada momento pode-se encontrar algo novo, uma surpresa com a qual não se está contando. E foi essa a direção que demos à pesquisa.

A perspectiva de investigar o trabalho dos docentes do ensino médio e a sua relação com o processo de saúde e doença deu-se em razão do quadro de precarização e deterioração das escolas que compõem o sistema de educação pública no Brasil, tão amplamente divulgado pela mídia. Esse quadro aponta a histórica forma de como os governos têm direciona- 
do os investimentos financeiros em políticas públicas em nosso país. Assim, o campo da educação tem vivido um processo crônico de insuficiência de financiamentos, gerando um processo de sucateamento do sistema público, em que ganha visibilidade, entre outros aspectos: a diminuição do número de professores e profissionais de apoio, como serventes, merendeiras, técnicos administrativos; a inexistência de condições materiais de trabalho, como estrutura física precária; a escassez de materiais pedagógicos; e equipamentos insuficientes ou sem manutenção.

Cabe destacar que o conceito de saúde que utilizamos aqui não se refere a um estado de equilíbrio ou ausência de doença. Concebemos a saúde como um processo de luta dos humanos diante dos obstáculos da vida. Dessa forma, a saúde, mais do que a possibilidade de viver em conformidade com o meio externo, implica, também, criação de novas normas em situações novas e, nesse movimento incessante, é criação de si mesma e de mundos. Como indica Canguilhem (2001), é próprio do ser vivo construir seu meio. A doença, por sua vez, constitui a dificuldade de criar novas normas de vida diante da diversidade das situações que se vão forjando no meio.

Nosso interesse nesse estudo era, portanto, compreender como a organização do trabalho se tem materializado no campo educativo e qual sua relação com o processo de saúde e doença do professorado que atua na rede estadual de ensino do Espírito Santo. Perguntávamos: Quais estratégias são inventadas por professores e professoras para dar conta de seu trabalho, marcado, muitas vezes, por condições adversas, e quais delas se configuram como movimentos de resistência (como reexistência) e, portanto, apontam para a produção de saúde? Como o professorado, mais do que trabalhar em conformidade com as formas instituídas nas escolas, institui novas normas sempre que se depara com situações novas no curso do seu trabalho?

Essa investigação foi ancorada nos estudos da ergologia e da psicodinâmica do trabalho para entendermos a complexidade das inter-relações entre trabalho e saúde, e apontarmos como os docentes lidam com os imprevistos em situação de trabalho, abor- dando o processo de criar e recriar formas de fazer e suas implicações para os resultados do trabalho e para o processo de saúde dos sujeitos.

A ergologia apropria-se de conceitos das diferentes disciplinas que apontam as (re)singularizações parciais, inerentes às atividades de trabalho. Segundo Schwartz (2002, p. 135), o que importa à ergologia "no campo das atividades humanas é sempre, num certo grau, história". Assim, contribui para a reflexão sobre a atividade humana sem neutralizar as singularidades e os aspectos históricos (Schwartz, 1998). É nesse sentido que sinaliza, conforme Canguilhem (2001), que a relação humano/meio de trabalho é sempre mais ou menos produção de normas que constituem a possibilidade de o vivo produzir saúde e a transformação do seu meio.

Ao enfocar a atividade, a ergologia aborda "as normas antecedentes e as variabilidades, as normas que se impõem e as normas que se instauram" (Brito, 2003, p. 24), entendendo o trabalho como um lugar de problematizações, ou seja, um lugar que convoca os sujeitos a fazerem escolhas no sentido de se dar novas normas, tornando a vida possível de ser vivida no meio de trabalho. Aqui se opera a concepção do trabalho como "usos", na medida em que a relação humano/ trabalho é sempre um "encontro histórico" em que os saberes científicos consolidados nos modos de organizar o trabalho e os saberes da prática se confrontam, permitindo o caminhar da história humana.

Schwartz (2000) esclarece que nas situações de trabalho se realiza um "encontro" no qual há sempre um destino a ser vivido, uma "dramática" em que os sujeitos têm que fazer escolhas, arbitrar entre valores diferentes, muitas vezes contraditórios, uma situação em que cada um deve gerir sua atividade de um modo ou de outro.

Em outras palavras, dizemos que não existe situação de trabalho que não convoque "dramatiques do uso de si", as quais se prendem aos horizontes de uso dentro dos quais cada um avalia a trajetória e o produto, ao mesmo tempo individual e social, do que é levado a fazer. (Schwartz, 1998, p. 107) 
Foi essa concepção de trabalho que norteou o nosso estudo, pois entendemos que os sujeitos não se restringem à pura execução das tarefas prescritas pela organização do trabalho, entendido como espaço da vida em que homens e mulheres vivenciam escolhas entre as formas cristalizadas de trabalho historicamente construídas - trabalho prescrito - e o trabalho concreto que apresenta variações, imprevistos à execução de sua tarefa, ou seja, o trabalho real, conforme sinalizam os estudos da ergonomia de linhagem francesa. Portanto, como conclui Dejours (1997, p. 40), "o real está consubstancialmente ligado ao fracasso. É aquilo que no mundo nos escapa e se torna, por sua vez, um enigma a decifrar. O real, então, é sempre um convite a prosseguir no trabalho de investigação e de descoberta".

Para a ergologia, a instituição de novas normas é o que dá sentido ao trabalho e ao movimento da vida. É uma forma de tornar o trabalho "vivível". Segundo essa abordagem, a atividade está sempre a exigir uma reavaliação do meio e das normas de trabalho. O que explica essas reinvenções e sua dinamicidade é a possibilidade do retrabalho, de renormalizar os protocolos que se antecipam às situações reais de trabalho. A renormalização fala de uma necessidade do vivo de redefinir seu meio e instituir para si normas diferenciadas de vida e saúde. "Os atos de trabalho não encontram o trabalhador como uma massa mole onde se inscreveria passivamente a memória dos atos a reproduzir" (Schwartz, 2000, p. 41).

Podemos considerar as arbitragens entre os procedimentos e os imprevistos "inteligências astuciosas" (Dejours, 1997) que resistem às objetivações e delimitações protocolares. Schwartz (2000) prefere denominar essas microcriações de "corpo sì" porque são sempre atravessadas por uma inteligência que marca essas escolhas diante da atividade e nem sempre são conscientes. Uma inteligência do corpo que atravessa os músculos, os líquidos, os nervos, a postura, o imaginário, mas não se restringe apenas ao biológico nem apenas ao cultural, antes perpassa todos esses circuitos. "É história, mas da história que funciona nas alquimias que vão além de nós: e que vão além tanto de quem lhe mostra o espelho quanto de quem está diante dele" (Schwartz, 2000, p. 13). O "corpo si" é algo que escapa às cristalizações e que remete à história, à experiência, às paixões daqueles que trabalham para dar continuidade ao movimento da vida.

Trata-se do "fator humano", que opera nas situações de trabalho desmitificando a concepção do trabalho como mera execução. No entanto, escolher é sempre um risco que nos coloca na ilegalidade em relação às prescrições. Essa "astúcia" que se antecipa às prescrições pelo revés do real ao mesmo tempo implica uma subversão às normas protocolares que se produzem na intimidade do "encontro", no segredo e ao abrigo dos olhares externos da hierarquia (Dejours, 1997).

Mas o segredo "do uso de si" pode ter conseqüências desvantajosas para os sujeitos, na medida em que as "dramáticas" os colocam na solidão, na dissimulação perante o coletivo de trabalho. Desse modo, a atividade impõe a responsabilidade aos que trabalham pelas suas microdecisões: "responsabilidade pelo desrespeito às instruções, responsabilidade pelos riscos que esses macetes podem causar à segurança e até à qualidade" (idem, p. 51). Os usos "de si" são atos técnicos que precisam ser publicizados para que haja o reconhecimento das habilidades, dos talentos dos sujeitos. Entretanto, dar visibilidade a um ato ilegal pressupõe uma voluntariedade, de um lado, e a confiança nos pares, de outro.

Como dissemos, o conceito de fator humano não pode ser estabelecido somente sobre a dimensão individual da relação sujeito-tarefa. Ela deve ser pensada a partir da intersubjetividade e das interações (onde a visibilidade é uma forma particular) no coletivo de trabalho. (idem, p. 53)

As relações de confiança que regem um coletivo de trabalhadores são guiadas por valores éticos e crenças que são fundamentais para a coordenação das atividades e dos fazeres que contribuem para alterar as regras prescritas da organização do trabalho. A arbitragem coordenada é uma atividade normativa, na medida em que são construídas as normas de traba- 
lho nas quais todos estão engajados. Nesse ponto, podemos diferençar a organização prescrita e a organização real de um coletivo de trabalho. "A gestão cotidiana da distância entre a organização prescrita do trabalho e a organização real implica, pois, além disso, a visibilidade dos modos operatórios reais, de arbitragens repetidas que são necessárias à coordenação" (idem, p. 57).

Segundo Dejours (1997, p. 94), a cooperação é esse lugar organizador para onde convergem as diferentes contribuições dos sujeitos no ambiente de trabalho. "A cooperação é o nível de conjugação das qualidades singulares e de compensação das falhas singulares". Portanto, o processo saúde/doença e a qualidade do que se produz estão, intrinsecamente, relacionados com a cooperação, a confiabilidade, os valores morais e éticos estabelecidos entre as pessoas no meio de trabalho. Na medida em que entendemos o trabalho como um meio que solicita arbitragens, engajamentos e escolhas, podemos pensá-lo como patogênico se essas interlocuções entre homem/mulher-tarefa e com os pares ficarem impossibilitadas ou reduzidas.

Conforme Canguilhem (1990), o que caracteriza o ser vivo é a sua capacidade de ser normativo, ou seja, a possibilidade que a vida encontra de instituir normas em condições diferentes do meio, o que significa poder acompanhar as transformações que a vida está sempre a produzir. Ter saúde é poder tolerar as infidelidades do meio, pois a normalidade constitui a capacidade de experimentar essas infrações. Então, "o doente não é anormal por ausência de norma. E sim por incapacidade de ser normativo” (p. 148).

Desse modo, visualizamos a saúde como a possibilidade de introduzir modificações na realização da tarefa, as múltiplas formas de criação e de iniciativas que os seres empreendem e que diferenciam o trabalho prescrito do trabalho real (Santos, 2000, p. 127). Então, a saúde no meio de trabalho é a possibilidade de afirmar a criação, alternativas, reajustamentos para os imprevistos que a tarefa exige, é ser normativo. Compreendemos que ter saúde
[...] é assinalar a capacidade que temos de desmontar algo que já recebemos pronto e que nos faz mal, desenvolvendo as condições estratégicas para a criação de novas regras, de acordo com nossos interesses, escolhendo estilos de vida alternativos às adversidades, dando um jeito próprio, singular, ao já dado. (Athayde, Brito e Neves, 2003, p. 29)

Com base nesses pressupostos, o que nos interessou sobremaneira foram os aspectos do trabalho que problematizam os protocolos, e ainda como os sujeitos, em seu cotidiano, colocavam em ato a história se fazendo. Entendemos que é por meio desses engajamentos que os humanos reinventam sua tarefa e a si mesmos, constituindo um indicativo de saúde. Assim, pretendíamos compreender como os sujeitos lidam com as adversidades das situações de trabalho e como constroem estratégias para o seu enfrentamento, uma vez que, ao focar essa luta e potencializá-la, podemos estar criando uma via importante para a transformação da realidade vivida hoje nas escolas, conforme sinalizamos.

\section{A construção de labirintos-polivalentes e as condições de trabalho}

Como têm sido construídos os labirintos por esta terra? Em que momento histórico emerge essa idéia de construir labirintos-polivalentes nestes territórios do Brasil? A inauguração do nosso labirinto-escola acontece em 1976, durante os governos da ditadura militar iniciada com o golpe de 1964.

Que objetivos e desejos atravessam os pensares desses Minos $^{2}$ brasileiros? Entre tantos, podemos falar da vontade de aproximação com o capital estrangeiro, especificamente o norte-americano, com o ob-

\footnotetext{
${ }^{2}$ A expressão "Minos" é usada no sentido de governo, man-
} datários de certo poder decisório, fazendo referência ao rei de Creta, Minos, da mitologia grega, conforme explicitado na nota ao título do artigo. 
jetivo declarado de combater a expansão do comunismo soviético. Instalou-se à força um "Estado que tinha como tarefa concreta a eliminação dos obstáculos à expansão do capitalismo internacional" (Ribeiro, 1995, p. 185). Assim, Minos-estrangeiros e Minos-brasileiros associaram-se, e os resultados dessa aproximação entre Brasil e Estados Unidos surgem na educação a partir dos estudos do Instituto de Pesquisa e Estudos Sociais (IPES), assessorado pela Agência Internacional de Desenvolvimento (AID), com o estabelecimento de vários acordos, denominados "Acordos MEC/USAID”.

A articulação entre esses organismos forneceu subsídios que nortearam as legislações educacionais produzidas nessa época. É nesse período da história brasileira que as reformas do ensino contidas na lei n. 5.692/71 passam a ter uma inspiração economicista e indicam o estabelecimento de relações diretas entre educação e produção. É dessa forma que o ensino secundário "deveria perder suas características de educação 'propriamente humanista' e ganhar conteúdos com elementos utilitários e práticos" (Ghiraldelli Júnior, 1994, p. 169).

Oh, eu percebia que quando eu queria fazer um trabalho do tipo: vamos coletar, fazer alguma coisa diferente, na hora do trabalho eu era impedida de fazer. "Não, mas você não podia ter feito isso" [imita a voz de alguém]. Você tinha que ter falado não sei com quem, com a supervisora, orientadora. Você nem encontrava com elas. Você nem via, e no final não tinha nem supervisora mais, entendeu? Aí você perdia a graça, entendeu? Você não tinha apoio pra fazer as coisas, ir pra frente. O que você podia fazer era só falar, falar. (Professora A)

Segundo Souza (2003), o ensino brasileiro estruturado pela ótica do tecnicismo norte-americano produziu alterações na organização do trabalho na escola, fragmentando o trabalho pedagógico por meio da lei n. 5.692/71, que instituiu a presença de especialistas, como orientadores, supervisores, inspetores. $\mathrm{Na}$ concepção dessa autora, esse modelo de funcionamento tem raízes nos princípios da teoria geral da administração, nos quais se destaca a importância da divisão social do trabalho como uma forma de racionalização do trabalho escolar, enfatizando sua eficiência e produtividade.

O financiamento norte-americano para a educação no Brasil resultou na importação não só do modelo de organização do trabalho nas escolas, mas também do projeto arquitetônico para a construção de prédios escolares. Assim, construíram-se, neste país tropical, as chamadas escolas-labirinto-polivalentes, com salas herméticas e pouco ventiladas, características de países frios. Prevaleceu aí um ensino pré-profissionalizante, com disciplinas teóricas e práticas sobre técnicas industriais, comerciais, agrícolas, economia doméstica, entre outras.

Professora $\mathrm{H}$ - O projeto acho que é americano, né?

Entrevistadora - Da década de 1970?

Professora $\mathrm{H}$ - É, então quer dizer, pra países frios, com neve. Aqui... [dá risadas].

Entrevistadora - E é quente aqui à tarde, no verão?

Professora H - Nossa! Muito quente! Muito quente!

Construída na vigência do Programa de Expansão e Melhoria do Ensino (PREMEN), a escolalabirinto-polivalente que pesquisamos iniciou suas atividades atendendo alunos de primeira à oitava série do ensino fundamental. À medida que as políticas educacionais se foram transformando, houve necessidade de redefinir o funcionamento da escola. Tal labirinto foi ao sabor do vento ou dos Minos-políticos?

Durante o estudo de campo, a escola funcionava com cinco turmas de primeira série do período letivo de 2003 e duas turmas de quinta série. Do ano letivo de 2003/2004, havia uma turma de aceleração, três primeiras séries, uma turma de segunda e outra de terceira série, totalizando uma média de 350 alunos no turno matutino. A existência de dois calendários letivos nas escolas estaduais devia-se às constantes greves deflagradas no governo anterior (o governo do PSDB, 1998-2002), por falta de pagamento dos salários. Durante a pesquisa, encontramos um ano letivo com término em dezembro de 2003, que acolheu os alunos 
vindos da rede municipal, e outro calendário que se iniciou em junho de 2003, com término em junho de 2004. Aí estão os resquícios das ações dos Minos-políticos de nosso estado. Esses não devoram gente, como o Minotauro da lenda, mas há fortes indícios de que devoram money.

Nos últimos anos, a imprensa do estado tem veiculado reportagens sobre as condições de trabalho nessas escolas-labirinto. Os temas das matérias quase sempre se repetem: são escolas sem teto, alagadas pelas chuvas, sem água, sem carteiras, sem merenda escolar e com a rede elétrica destruída. Em muitas turmas, o número de alunos passa de 45 . As salas parecem um auditório, sem microfone, com apenas um ventilador funcionando e outro quase despencando sobre as cabeças de professores e alunos.

Mas se você imaginar, por exemplo, você já reparou que isso tudo é coberto de isopor? Um princípio de incêndio e pega fogo em dois minutos. Quantos extintores de incêndio a gente tem nessa escola? Até hoje, já tem dois anos e eu não vi nenhum aqui. Então, o grande perigo que eu vejo nessa escola é a parte dos portões trancados, o material inflamável, a ausência de extintores, né? De segurança. (Professor D).

Recentemente, os temas abordados apontaram roubos e depredações, assassinato de estudantes e porteiros, drogas, agressões diversas contra o conjunto de trabalhadores da educação e a falta de segurança de forma geral.

Eu faço de conta que isso nem existe [as drogas]. Os bandidos sabem quem são os professores, que tipo de carro eles têm, a cor, tudo. Os bandidos sabem até a marca do som que tem no meu carro. Já pensei em falar sobre isso muitas vezes, mas depois eu pensei bem e desisti. Quando o assunto surge, eu digo: vocês querem ficar doidão? É só trabalhar um mês ganhando duzentos reais que vocês vão ver o que é ficar doidão. (Professor I)

Outro aspecto que merece destaque é a não realização de concursos públicos há mais de dez anos. $\mathrm{O}$ último concurso público para professores promovido pelo estado do Espírito Santo foi no ano de 1993. Em 2002, o governo realizou um concurso que foi cancelado em virtude das denúncias de irregularidades. Esse quadro tem prolongado a contratação temporária, tanto do professorado e da área administrativa quanto da área de apoio. Esses contratos sinalizam para uma situação precária de trabalho, na medida em que se iniciam em fevereiro ou março e se encerram em dezembro, ficando os trabalhadores a eles submetidos desempregados de dois a três meses por ano.

O relatório (Espírito Santo, 2002) da Comissão Permanente de Acidente em Serviço e Doença Ocupacional (CPASDO), do Setor de Perícia Médica da Secretaria Estadual de Administração e Recursos Humanos do Espírito Santo (SEAR), detectou a categoria do professorado como a mais acometida pela disfonia. "O fato é que, desses professores, embora ausentes das salas de aula, em tratamento médico e fonoterápico, poucos são os que se recuperam e retornam às suas atividades normais de trabalho" (p. 36). O referido relatório aponta 21 casos de doença ocupacional, e todos se referem à categoria docente com idade entre 30-59 anos e do sexo feminino.

Falar demais [...] se eu falar no mesmo nível deles, bem baixinho, eu não vou ter a atenção que eu necessito. Então, às vezes, eu tinha que esticar um pouquinho a voz. Eu acho que o maior problema relativo à saúde é a questão da voz. A questão da voz, a voz realmente é o que me desgastava mais. (Professor I)

Percebemos que essa situação vivida pelos docentes do estado do Espírito Santo se vem agravando nas últimas décadas em decorrência das políticas públicas adotadas no país. Trata-se de ressonâncias que, entrelaçadas e produzidas pelos embates gestados nos anos de 1970 e 1980, geraram seus efeitos nas reformas educacionais dos anos de 1990, quando se encontrou um terreno propício para frear as reivindicações populares por meio de diversas tentativas de cooptação e codificação de lutas dos educadores, a partir de pressupostos da produção e do capital internacional. Segundo uma professora: 
[...] tiravam tudo, como tiraram aquelas reuniões de quinta-feira que eram tão legais. Então, só tiraram. Só houve perdas pra gente. Então, eu comecei com uma perda muito forte e depois só houve perdas. Eu fiquei muito [...]. Que só houve perdas na educação. Só perdas, perdas. Só perdia tudo. Não teve ganhos. O que nós tínhamos ganho, direitos adquiridos, nós tínhamos perdido. (Professora A)

\section{Entre Teseus e Minotauros: a escola-labirinto polivalente como "espaço de possíveis"}

Constatamos que a imprevisibilidade do real e a variabilidade das situações de trabalho com que os docentes se deparam a cada manhã na escola envolvem diferentes processos decisórios que apontam para a gestão micropolítica da atividade. Desse modo, entendemos que, embora em condições muito adversas de trabalho, que estavam/estão produzindo um processo de adoecimento, a escola também se constitui num "espaço de possíveis", em que os sujeitos se manifestam no ato de trabalho por meio da "atividade industriosa" (Schwartz, 2000, p. 32), pela diversidade de "usos de si" que sinalizam para a afirmação do movimento da vida e da saúde. Segundo Wisner (1994, p. 19), "uma das características mais notáveis dos seres vivos é a diversidade de suas reações numa dada situação".

São os resultados, né? Que me agradam. É essa coisa que me instiga [...]. E isso é legal pra mim, porque eu já entro em sala de aula e você vai modificando [...]. Então, quando você vem com uma metodologia diferente, com uma proposta diferente [...]. Isso me dá mais energia, me faz revigorar, entendeu? Porque eu acho que é bacana, aí quando você vê o resultado do que a gente faz, quando chega aqui... (Professor D)

O trabalho desenvolvido na escola-labirinto possui uma multiplicidade de solicitações que vai incitando os docentes a ultrapassarem as formas instituídas de fazer educação. Assim, "descortinava-se” uma gama de práticas inventivas que visavam dar conta de uma multiplicidade de variáveis presentes naquele cotidiano de trabalho.

Então, eu não sou um cara que paro. Eu tô 24 horas pensando em outras coisas. Levar meus alunos pro cinema. Eu tô marcando com cinco, seis alunos pra viajar pra Ouro Preto no final do ano. Então, a minha cabeça é um processo, tá sempre em movimento. Eu tô sempre inventando coisas novas que tirem os alunos um pouco de sala. Eu acho que sala de aula é um pouco maçante. (Professor I)

Identificamos que professores e professoras afirmam uma capacidade avaliativa do seu trabalho na medida em que estão constantemente repensando e construindo formas de tornar a escola e o ensino menos maçantes para os discentes. Historicamente, há uma concepção mecanicista da relação de homens e mulheres com o meio de trabalho. A racionalização das atividades e a subjugação do homem no modelo taylorista seria, na concepção de Canguilhem (2001), uma ilusão tecnicista, pois, partindo-se dessa visão, os trabalhadores apenas reagiam às estimulações do meio físico, não lhes sendo possível pensar nem escolher a forma de execução das suas tarefas. Durante o processo de pesquisa, foi possível conhecer a capacidade daquele professorado de estabelecer uma relação ativa como produtores da escola, em que não apenas se submetem às suas coerções, como também a interpretam, avaliam, corrigem e organizam como um "novo meio".

O meu trabalho é o quê? Teatro, é música, retroprojetor, música, música, música, muita música de Caetano, Zé Ramalho. Então quer dizer: realmente quebra. Mas chega uma pessoa que faz um teatro, faz alguma coisa que vai além da sala. Você toca uma música, leva um retroprojetor pra dentro de sala. O que acontece? Desnivela. Eu tinha um trabalho diferente [...]. Outra coisa: eu ia quase todo sábado na escola jogar bola, fazer teatro, passar filme. Fazíamos sessões, no final de semana, de filmes na escola. (Professor I)

A fala do professor deixa transparecer a emergência de formas de fazer que traduzem o "encontro" 
entre o sujeito e as normas prescritas, horários de entrada e saída, tempo de exposição dialogada em sala de aula, calendários, determinação de uso dos espaços, modelo de ensino centrado no professor, relações hierarquizadas, o tempo determinado para a finalização dos contratos de trabalho etc., que correspondem às regras preestabelecidas e sem a prévia anuência dos professores, as quais é preciso sempre quebrar, retrabalhar para produzir um "desnivelamento". A atividade real efetivada pelos sujeitos envolve a escuta de música, a encenação teatral, a exibição de filmes ou jogos de futebol nos fins de semana, configurando uma nova apropriação dos espaços e equipamentos, apontando a construção de maior aproximação entre a comunidade discente, a escola e os professores.

Para Schwartz (2003), a filosofia da "organização científica do trabalho" proposta por Taylor pretende anular a dimensão do "encontro" entre o ser vivo e seu meio de trabalho, mas esse é sempre um momento em que a história se produz, na medida em que os sujeitos se criam e se recriam dialeticamente aí. Como dizem Athayde e Figueiredo (2004, p. 254), "as almas nunca estiveram ausentes nos mundos do trabalho, nem podem ser capturadas por completo". Essa capacidade de inventar novas normas, recriar o trabalho e transformar as configurações culturais, técnicas e sociais no campo da educação, para torná-lo vivível, expressava-se em muitas ações do professorado:

[...] e eu, quando saía com os alunos, eu falava: só vou sair com vocês em fila. Então, todo mundo fazia fila. $\mathrm{Na}$ hora que fazia a fila, por exemplo, estamos numa sala e aqui tem um portão pra abrir. Aí tem aquele quadrado que é o espaço das salas. O que eu fazia? Na hora de ir pro portão, ir pra sala, eu dava aquela volta tipo um oito, pra gente poder sair. Era uma brincadeira. Segue o sistema? Não. Tem que ser padronizado... Quer dizer, isso dava polêmica dentro da escola. É fugir um pouquinho do padrão. São poucas coisas que cativam o aluno. Pouca coisa que agrada. Você vai com o aluno pra fora de sala, no meio da aula, contar uma piada. Então, são poucas coisas que tornam a aprendizagem mais fácil. (Professor I)
As normas prescritas foram constantemente referidas pelos docentes como "padrão", "sistema", "regra", que era preciso subverter para que pusessem a bom termo seu trabalho e o processo de aprendizagem. Identificamos que uma estratégia muito utilizada era ministrar aulas no pátio da escola, fugindo não apenas do espaço preestabelecido (sala de aula), mas também da própria formatação do conteúdo que deveria ser ministrado. Em outras ocasiões, discutiam com os alunos e as alunas a posição deles a respeito de matérias de jornais e programas de TV para adolescentes, relacionando-os com o vivido, subvertendo os "conteúdos curriculares maçantes" e, assim, produzindo outros sentidos para esse currículo. Circular pelos corredores do labirinto-escola com discentes era uma outra forma de "exibir", "contaminar", procurando subverter a prescrição das rotinas de trabalho. Isso constitui o que Schwartz (2003) denomina de "renormalizações da história", isto é, um outro processo de educação, de relações intersubjetivas e da instituição escolar sendo produzido por meio dessas ações microestratégicas.

Fazer, trabalhar com um assunto que é praticamente novo. Porque quando você fala em altas habilidades e superdotação, a maioria desconhece. É um trabalho que te leva a estar sempre estudando, buscando mais, e o fato de você saber que está sendo útil a alguém [...]. É sempre uma troca. Cada dia a gente aprende uma coisa nova. Com os alunos, com os colegas. Tem sempre uma troca [...]. E às vezes um acrescenta uma coisa nova. Há uma troca muito grande. Nós aprendemos com os pais. Tem a troca com os professores da escola regular onde esses alunos estão inseridos. Então, é uma interação muito grande. O Programa de Apoio ao Aluno Talentoso não é... como vou dizer?... não tem rotina. É todo dia uma coisa nova. Cada dia é um dia novo, e por mais que você trabalhe aqui, você não sai daqui cansada. (Professora P)

Podemos afirmar que o trabalho do professorado é um lugar de variabilidades que coloca problemas e questões para os sujeitos, indicando a distância entre o prescrito e o real. As atividades são referidas 
como algo em constante movimento, que não se prendem a rotinas, nas quais a cada dia "coisas novas" se presentificam, gerando nos sujeitos a realização e o prazer, inclusive experienciado no corpo, quando este sinaliza a ausência do cansaço. Embora a prescrição polarize algumas formas de fazer, os sujeitos não se restringem à sua obediência, já que o trabalho os incita a elaborar respostas relevantes para os eventos não previstos pela organização do trabalho.

A referência às tentativas de criar modalidades diferentes de aprendizagem, assim como as trocas com outros atores da comunidade escolar (pais, alunos), apontam as iniciativas que se vão introduzindo no cotidiano de trabalho, no qual os procedimentos prescritos são (re)tratados, reapreciados por meio da criação de estratégias reguladoras em que se chega aos resultados almejados. As relações de troca constituemse como prioridades nessa organização do trabalho, gerando, no professorado, o sentimento de que seu trabalho é útil para a produção social. É desse modo que se produz o sentimento de "pertença" a um coletivo cujo trabalho ganha sentido na vida dos sujeitos e engendra o processo de saúde.

Tanto que nesse teatro pra mim aqui eu não analisei meus alunos pelo resultado. Eu analisei o processo. E no processo eu me diverti mais do que eles. Eu até chegava em casa cansado de tanto que eu gesticulava, que eu rolava, que eu ria. Isso pra mim é saúde. (Professor I)

Ao transitar por uma escola que apresenta condições de trabalho nocivas à saúde, os Minotaurosdocentes antecipam-se a essas más condições, criando estratégias ou modos operatórios diferenciados diante da situação de precariedade presente. Lembrando Dejours (1997), como explicar que, mesmo se confrontando com situações de trabalho adversas, em um ambiente infiel, nem sempre adoecem? Conforme esse autor, isso é possível em função do "reconhecimento", ou seja, o que retorna para os sujeitos, o fato de eles trabalharem, as redes sociais que mantêm determinado trabalhador no seu posto de trabalho:
Do reconhecimento depende, na verdade, o sentido do sofrimento. Quando a qualidade de meu trabalho é reconhecida, também meus esforços, minhas angústias, minhas dúvidas, minhas decepções, meus desânimos adquirem sentidos. Todo esse sofrimento, portanto, não foi em vão; não somente prestou uma contribuição à organização do trabalho, mas também fez em mim, em compensação, um sujeito diferente daquele que eu era antes do reconhecimento. (p. 34)

Os trabalhadores seriam, portanto, sujeitos capazes de viver simultaneamente prazer e desprazer, e, por conta disso, desenvolvem estratégias individuais e coletivas para enfrentar essas situações. Trata-se de uma postura sempre propositiva em suas relações com o movimento da vida, em que é necessário estar em luta contra as infidelidades do ambiente. $\mathrm{O}$ aparecimento da doença, reafirmamos, advém da diminuição dessa capacidade de ser normativo, de ultrapassar as normas presentes e criar outras mais condizentes com as situações novas que se configuram incessantemente no meio externo.

É porque... esse tipo de evento, na verdade, ele te deixa agitado, te leva a isso aí. Mas depois a gente dá um... te relaxa, porque você vê os resultados. Então, você vê uma animação na escola. Se consegue ver um resultado. Então, não dá pra ficar estressado. Estressado, sim, se você chegasse e não conseguisse um coral, ficasse a mesma coisa. Ficasse sentado aqui, parado assim, reclamando: "Ah, os alunos aqui são isso, os alunos são aquilo, e não se toma atitude nenhuma". Eu acho que isso me deixaria de fato estressado. (Professor D)

Essa fala expressa a necessidade vital do humano em não se resignar às condições dadas de trabalho. "Ficar assim reclamando" e não gerir constantemente seu meio de trabalho resultaria na conservação das normas e no processo de adoecimento. Assim, o fazer diferente assume importância capital para a saúde, na medida em que adoecer seria paralisar nas condições oferecidas pela escola, apontando que esta é a "dramática”, o "destino a ser vivido" pelo profes- 
sorado em cuja atividade se cruza o "o uso de si pelo si e pelos outros". Trata-se das escolhas que os humanos têm de realizar para fazer valer suas próprias normas de vida, produzindo formas de "desanonimar" o meio. No depoimento anterior, o professor afirma a saúde como um constante processo de luta e, por que não dizer, de riscos a que os docentes se submetem quando resolvem preencher as deficiências dos protocolos na busca pelos "resultados", ou seja, pela realização da tarefa proposta, o que, ao mesmo tempo, possibilita a transformação do trabalho na escola.

Eu dou prova no pátio. Naquele lugar do teatro. Como você vai dar prova pra quarenta e oito alunos um em cima do outro? Eu mando eles tirarem as carteiras e levarem pra lá. Outros professores viram o que eu estava fazendo e todo mundo começou fazer o mesmo, lá fora. (Professor I)

Embora nos tenhamos referido à capacidade normativa e à produção de saúde como algo que se processa no campo individual, na singularidade do corpo e na relação subjetiva do ser com o meio, queremos afirmar que a saúde também está referenciada a um meio social, histórico, político, cultural, que remete a uma história coletiva condensada e presente nas regras de trabalho, às quais todos estão subordinados. As condições nocivas à saúde na escola, e impostas a todos, apontam um meio social que é preciso gerir de outro modo, no qual, ao lado da realidade de trabalho, novas formas de viver possam ser construídas. Em uma das falas, fica evidente que as salas pequenas e o grande número de alunos constituem não só um aspecto limitador para a realização do processo de avaliação dos discentes, mas, principalmente, reafirma a precariedade das condições de trabalho. Submissão a essas condições?

Conforme Dejours (1993, 1997) e Dejours, Abdoucheli e Jayet (1994), a introdução de ajustes ou "quebra-galho" na organização do trabalho revela a integração de sujeitos num jogo coletivo, já que a engenhosidade empregada é necessária ao estabelecimento da organização real e à eficácia do trabalho. Esses "macetes" inventados ante a atividade são, por um lado, modos operatórios que se situam fora da tradição e da norma, ou seja, consistem numa subversão às regras prescritas que apontam a ilegalidade das condutas. Por outro lado, constituem "achados técnicos" que precisam ganhar visibilidade e se constituem como questionamento dessas condições de trabalho, porquanto possibilitam o controle dessas práticas pelo coletivo e seu reconhecimento pelos pares, em termos de habilidade e talento. A transparência é fundamental para fazer-se a passagem da engenhosidade do nível subjetivo para a sua efetivação no concreto de trabalho. A publicidade do "quebra-galho" é necessária para criarem-se relações de confiança entre colegas e hierarquia, visto que a confiança é fundamental para a instituição da cooperação num coletivo de trabalho. Para Dejours (1993), o que caracteriza e funda um coletivo de trabalho é o sistema de cooperação entre os agentes que trabalham. Caso contrário, a simples reunião espacial ou temporal de agentes não se trata, necessariamente, de um coletivo de trabalho. A confiança num coletivo é uma relação intersubjetiva e afetiva que possibilita a visibilidade dos macetes, a coordenação e a cooperação, estando, portanto, ligada à satisfação e ao prazer no trabalho.

O "quebra-galho" é uma liberdade que se toma em relação à organização prescrita, e a sua publicidade abre a possibilidade de criação de um espaço de discussão sobre as condutas transgressivas, retirando do âmbito individual a responsabilidade e a angústia pelos riscos que se corre diante da organização do trabalho. A partir do momento em que os docentes compartilham desses ajustes feitos na organização do trabalho na escola, eles integram-se num jogo coletivo, demonstrando que relações de confiança aí se estabeleceram. Isso aponta a persistência da vida, que constrói uma nova norma diante de situações contra as quais é preciso lutar para poder continuar a viver e produzir a saúde. "A vida não é, portanto, para o ser vivo, uma dedução monótona, um movimento retilíneo. Ela ignora a rigidez geométrica, ela é debate ou explicação com um meio em que há fugas, vazios, esquivamentos e resistências inesperadas" (Canguilhem, 1990, p. 159). 
Mas eu acredito que o ser humano tem que fazer o que gosta. Acho que a vida da gente é muito curta. Me veio à cabeça de fazer o trabalho sobre o "Operário em construção", de Vinícius, né? Porque eu me tornei professor de português... que destino? "O operário em construção" me trouxe pra sala de aula, pra falar sobre o operário em construção. Então, o que foi que aconteceu? Fiz o projeto, foi aprovado. (Professor I)

Essas condutas propositivas em relação ao meio de trabalho são denominadas por Dejours (1997, p. 46) de "inteligência astuciosa", e referem-se a uma mobilização subjetiva criadora e inventiva em uma situação real de trabalho. Significa que outros modos operatórios são produzidos pelos trabalhadores para enfrentar aquilo que não pode ser feito pela estrita obediência às normas prescritas. É uma inteligência inscrita no corpo e no pensamento, que se engaja nessa relação com o trabalho com o objetivo de antecipar-se às "situações inéditas, ao imprevisto, frente a situações móveis e cambiantes” (Dejours, 1997, p. 46).

A fala citada mostra a presença dessa inteligência astuciosa que os sujeitos materializam no espaço de trabalho na escola. O professor sinaliza que o poema "Operário em construção" atravessa sua história e vida profissional, na medida em que verbaliza: "Então, eu acho que, se hoje eu sou professor, foi o operário em construção. Eu estou em construção. Eu gosto do que faço". Assim, a criação de um teatro musical sobre a vida e a obra de Vinícius de Moraes tornou-se um dispositivo que mobiliza os alunos e tantos outros professores e professoras em sua elaboração. Para sua apresentação, docentes e discentes unem-se como atores da peça.

Na concepção de Schwartz (2000), essa convocação dos sujeitos para tomarem decisões em relação à atividade remete ao "corpo si". Nessa concepção, o trabalho é concebido como um lugar de "encontro", uma experiência em que se cruzam os diversos vetores da história humana, técnicos, econômicos, políticos, sociais, científicos, os quais não conseguem determinar, antecipar por completo o que se vai produzir no concreto da atividade. Para o autor, esses vetores estão configurados como "concentrados de história" sempre incompletos, o que possibilita aos humanos reescrevê-los, renormalizá-los constantemente onde quer que se reúnam para produzir (Schwartz, 2003), sinalizando a atividade como lugar em que coexistem o "uso de si pelo si" e "pelos outros".

Quando iniciamos nossas andanças pela escolalabirinto, percebemos que existiam normas contrárias à afirmação da vida e da saúde. Mas encontramos também uma multiplicidade de recursos e capacidades inventados pelos sujeitos para gerir essas infidelidades do meio, entre as quais as relações de proximidade com alunos, a criação de projetos diferenciados que propiciam maior interesse e aprendizado dos estudantes, a gestão inventiva das aulas e dos espaços da escola; a criação de estratégias coletivas e de cooperação.

\section{Considerações finais}

O intuito deste estudo foi apontar as relações entre o trabalho de professores de uma escola pública do estado do Espírito Santo e o seu processo de saúde/ doença. Partimos do princípio de que o modo de funcionamento de uma escola, ou seja, a forma como se organiza o trabalho nos estabelecimentos educacionais, contribui para a constituição de sujeitos. Consideramos que a gestão e as práticas profissionais têm a potência de modificar os sujeitos e os padrões dominantes de subjetividade. Têm, portanto, potencial pedagógico e terapêutico, seja para criar dependência e impotência, seja para co-produzir autonomia, ampliando a capacidade de análise e de co-gestão (Campos, 2003). Foi nessa direção e com essa preocupação que trouxemos a situação de precariedade das condições de trabalho na escola e a forma como o trabalho aí se organiza.

Entretanto, falar dessa situação não seria novidade, na medida em que isso não nos ajuda a repensar essa realidade a partir da resistência que os sujeitos já empreendem dentro dessas condições nocivas para produzirem suas atividades, sua saúde e a si próprios. Não estamos com isso querendo dizer que as condições de nocividade não devam ser transformadas porque, de alguma forma, os docentes já realizam sua 
modificação. Consideramos, com Athayde e Figueiredo (2004), que chamar a atenção para as adversidades do trabalho nas escolas é importante, mas seria um equívoco limitar nossa análise ao campo das denúncias. Ao contrário, é preciso evitar "que um certo tom de ressentimento ganhe vulto, bloqueando nossa escuta para os devires sempre presentes nas fendas da vida, para a potência da vida" (p.256).

O nosso objetivo, neste estudo, ao dar visibilidade às estratégias instituídas por professores e professoras para driblar as precárias condições de trabalho, é convocar as diferentes práticas no âmbito da psicologia e saberes afins a investirem na construção de uma outra realidade de trabalho na escola, potencializando essas microcriações já realizadas pelos docentes.

Nessa direção de análise, algumas questões se colocam ao final da pesquisa: O "drible em si" é produtor de saúde? Em que medida esses "dribles" nas precárias condições de trabalho funcionam como amortecedores e mantêm as coisas como estão, e, no mesmo movimento, podem funcionar como produção de saúde? Se não nos perguntamos sobre essas ações, podemos pressupor que o drible em si é produtor de saúde, tese com a qual não concordamos. Consideramos, auxiliadas pelas ferramentas conceituais de análise que utilizamos, que não há atividade de trabalho eficiente que se efetue fora de uma rede de trabalhadores. Os "dribles" precisam constituir-se como ingredientes para articulações, mesmo que fluidas e provisórias, entre os professores e as professoras, sendo condição fundamental para que se efetivem as atividades docentes.

Identificamos que há um engajamento coletivo, por exemplo, na estratégia de transferência de alunos da sala de aula para o pátio interno em dia de avaliação, o que constitui afirmação e reconhecimento da renormalização dos espaços da escola que dificultam a realização do trabalho dos docentes. Ao mesmo tempo, mostra o estabelecimento de relações de confiança entre pares e hierarquia, que (des)responsabilizam a criação individual como algo ilegal em relação à organização prescrita do trabalho.
Em relação ao prazer no trabalho, encontramos criação de normas por parte do professorado, por meio de teatros, de projetos culturais, de música, filmes, poesias, que transgridem as normas prescritas na escola, referidas como padrão, sistema e regras, afirmando o "uso de si pelo si" dos professores.

Não podemos deixar de assinalar que as estratégias inventadas no espaço da escola e explicitadas neste estudo precisam ganhar visibilidade/publicidade no coletivo e provocar a transformação da atual organização do trabalho. Acreditamos que é preciso abrir espaços de discussão a respeito do trabalho realizado, para que a luta pela saúde se constitua em redes de cooperação entre sujeitos e escolas e possa inaugurar outras formas de funcionamento da organização do trabalho na educação. Portanto, acreditamos que essas invenções que os trabalhadores já produzem em seu cotidiano devem ganhar espaço e visibilidade para potencializar formas coletivas de expansão ilimitada da vida e da saúde.

Mesmo em condições adversas, os sujeitos encontram prazer no trabalho porque a história humana só tem sentido por meio daquilo que não se consegue antecipar à experiência do encontro entre sujeitos e sua atividade (Schwartz, 2003). A satisfação tem a ver com o novo, com a recriação que constitui o processamento da história pela ação humana. Esse parece ter sido, afinal, o fio seguido pelos docentes implicados nesta pesquisa, que não desistem de encontrar a saída possível do labirinto-escola.

\section{Referências bibliográficas}

ATHAYDE, Milton. Psicologia e trabalho: que relações? In: JACÓVILELA, Ana Maria; MANCEBO, Deise (Orgs.). Psicologia social: abordagens sócio-históricas e desafios contemporâneos. Rio de Janeiro: EdUERJ, 1999. p. 195-220.

; BRITO, Jussara; NEVES, Mary Yale. Cadernos de textos: programa de formação em saúde, gênero e trabalho nas escolas. João Pessoa: Universitária/UFPB, 2003.

ATHAYDE, Milton; FIGUEIREDO, Marcelo. Coletivos de trabalho e componentes subjetivos da confiabilidade em sistemas sociotécnicos complexos: considerações a partir da situação de 
trabalho em mergulho profundo na Bacia de Campos/RJ. In: ATHAYDE, Milton; FIGUEIREDO, Marcelo; BRITO Jussara; ALVAREZ, Denise (Orgs.). Labirintos do trabalho: interrogações e olhares sobre o trabalho vivo. Rio de Janeiro: DP\&A, 2004. p. 254-269.

BARROS, Maria Elizabeth Barros de; FONSECA, Tânia Mara Galli. Psicologia e processos de trabalho: um outro olhar. Revista Psico, Porto Alegre, n. 2, p. 133-140, 2004.

BRANDÃO, Junito de Souza. Dicionário mítico-etimológico da mitologia grega. Petrópolis: Vozes, 1991. v. I e II.

BRITO, Jussara Cruz de. Saúde do trabalhador: reflexões a partir da abordagem ergológica. Rio de Janeiro: [s.ed.], 2003.

CAMPOS, Gastão Wagner de Souza. Saúde paidéia. São Paulo: Hucitec, 2003.

CANGUILHEM, Georges. O normal e o patológico. 3. ed. Rio de Janeiro: Forense Universitária, 1990.

Meio e normas do homem no trabalho. Pro-Posições, Faculdade de Educação, UNICAMP, v. 12, n. 2/3, p. 38-52, 2001.

DEJOURS, Christophe. Coopération et construction d'identité en situation du travaille. Futur antérieur, Paris, n. 16, p. 41-52, 1993. . A loucura do trabalho: estudo de psicopatologia do trabalho. 5 ed. aum. São Paulo: Cortez/Oboré, 1997.

DEJOURS, Christophe; ABDOUCHELI, Elizabeth; JAYET, Christian. Psicodinâmica do trabalho: contribuições da escola dejouriana à análise da relação prazer, sofrimento e trabalho. São Paulo: Atlas, 1994.

DELEUZE, Gilles. Conversações. Rio de Janeiro: 34 Letras, 1992. .; GUATTARI, Felix. Mil platôs: capitalismo e esquizofrenia. Rio de Janeiro: 34 Letras, 1996. v. 3.

ESPÍRITO SANTO. Secretaria de Estado da Administração e Recursos Humanos. Relatório da comissão permanente de acidentes em serviço e doença ocupacional (CEPASDO). Vitória: Secretaria de Estado da Administração e Recursos Humanos, 2002.

GHIRALDELLI JÚNIOR, Paulo. A ditadura militar. In: (Org.). História da educação. 2. ed. São Paulo:

Cortez, 1994. p. 163-188.

PASSOS, Eduardo; BENEVIDES, Regina. Políticas da transversalidade ou a transversalização como método clínico-político. São Paulo: Instituto Therapon, 2003.

RIBEIRO, Maria Luisa Santos. História da educação brasileira: a organização escolar. 14. ed. Campinas: Autores Associados, 1995. SANTOS, Eloiza Helena. Ciência e cultura: uma outra relação entre saber e trabalho. Trabalho \& Educação, Belo Horizonte, n. 7, p. 127-143, 2000.

SCHWARTZ, Yves. Travail et philosophie: convocations mutuelles. Toulouse: Octares, 1992.

Os ingredientes da competência: um exercício necessário para uma questão insolúvel. Educação e Sociedade, Campinas, n. 65, p. 101-139, 1998.

. Trabalho e uso de si. Pro-Posições, Faculdade de Educação, UNICAMP, n. 32, p. 13-44, dez. 2000.

. Disciplina epistêmica, disciplina ergológica: paidéia e politéia. Pro-Posições, Faculdade de Educação, UNICAMP, v. 1, n. 37, p. 75-98, jan./abr. 2002.

. A abordagem ergológica do trabalho e sua contribuição para a pesquisa em administração. Trabalho apresentado no Seminário Internacional de Administração. Vitória: UFES, 2003. SOUZA, Rosangela Maria. Especialistas em educação ou pedagogos? O que mudou? Pedagogia Millenium, Revista Científica do Curso de Pedagogia da Faculdade Novo Milênio, Vila Velha, v. 3, n. 3, p. 34-52, 2003.

WISNER, Alain. A inteligência no trabalho: textos selecionados de ergonomia. São Paulo: Fundacentro, 1994.

MARINETE ROSA PEREIRA MASCARELLO, psicóloga e mestre em educação pela Universidade Federal do Espírito Santo (UFES), é professora assistente da Faculdade Salesiana de Vitória (FSV) e coordenadora do Núcleo de Atenção à Saúde do Trabalhador do Hospital Universitário Cassiano Antônio de Morais, da UFES. Com Maria Elizabeth Barros de Barros publicou: Percorrendo o labirinto: trabalho, relações intersubjetivas e a saúde de professores de uma escola pública (Pró-posições, v. 17, n. 50, p. 211-234, maio/ago. 2006) e Uma cartografia da concepção de saúde/doença e sua relação com os processos de trabalho dos educadores (Pró-Discente - Caderno de Produções Acadêmico-Científicas do Programa de Pós-Graduação em Educação, UFES, v. 9, n. 2, p. 95-106, jul./dez. 2003). Linha de pesquisa atual na FSV: "Educação física e cotidiano escolar”. E-mail: marinetepsi@ hotmail.com; marinetepsi@yahoo.com.br

MARIA ELIZABETH BARROS DE BARROS, psicóloga e doutora em educação pela Universidade Federal do Rio de Janeiro (UFRJ), com pós-doutorado na área de saúde coletiva/ saúde do trabalhador, na Escola Nacional de Saúde Pública (ENSP/ FIOCRUZ), é professora associada da Universidade Federal do 
Espírito Santo (UFES), atuando no Departamento de Psicologia e no Programa de Pós-Graduação em Educação. Além dos trabalhos com Marinete Rosa Pereira Mascarello, publicou: com R. Scarabeli, M. Bergamin e L. Ferraz, Saúde e trabalho: uma experiência num hospital universitário (Cadernos Saúde Coletiva, UFRJ, v. 12, p. 23-38, 2006); com Flávia Marchiorie Sonia Pinto de Oliveira: Atividade de trabalho e saúde dos professores: o programa de formação como estratégia de intervenção nas escolas (Trabalho, Educação e Saúde, Rio de Janeiro, v. 3, n. 1, p. 143170, 2005); com N. A. Lucero: A pesquisa em psicologia: construindo outros planos de análise. (Psicologia \& Sociedade, Porto Alegre, v. 1, 2005); com E. M. A. Aragão e Sonia Pinto de Olivei- ra: Falando de metodologia de pesquisa (Estudos e Pesquisas em Psicologia, Rio de Janeiro, v. 4, n. 4, p. 51-63, 2005), Não vale a pena economizar a vida para não gastar (Psicologia \& Sociedade, Porto Alegre, v. 16, n. 1, p. 2-7, 2004); com Carlos Minayo-Gomez: Saúde, trabalho e processos de subjetivação nas escolas (Psicologia: Reflexão e Crítica, Porto Alegre, v. 15, n. 3, p. 24-52, 2002). Participa das seguintes linhas de pesquisa na UFES: “Análise do trabalho no campo da educação em suas múltiplas vertentes" e "Políticas educacionais e saúde”.E-mail: betebarros@uol.com.br

Recebido em março de 2006 Aprovado em dezembro de 2006 


\section{Resumos/Abstracts/Resumens}

Marinete Rosa Pereira Mascarello e Maria Elizabeth Barros de Barros

Nos fios de Ariádne: cartografia da relação saúde-trabalho numa escola pública de Vitória-ES

Trata-se de estudo qualitativo abordando as relações entre saúde e trabalho de professores de uma escola da rede pública na cidade de Vitória, capital do estado do Espírito Santo. Seu objetivo foi cartografar as vivências de prazer e sofrimento dos docentes, principalmente as estratégias criadas para defenderem-se das nocividades do ambiente de trabalho e produzirem saúde. Afirma a indissociabilidade entre modos de trabalhar e modos de subjetivar, e constata que a deterioração do sistema público de ensino tem produzido seus efeitos no trabalho do professorado, comprometendo a saúde desses profissionais e gerando, muitas vezes, seu afastamento das funções por meio de licenças médicas ou mesmo abandono da profissão. Procura dar visibilidade às ações que apontam para a recriação do trabalho, mesmo dentro de condições adversas.

Palavras-chave: produção de subjetividade; trabalho prescrito e real; saúde e doença

\section{In the threads of Ariádne:}

cartography of the health-work relationship in a public school in Vitória-State of Espírito Santo This article is based on a qualitative study dealing with the relations between teachers' health and work in a school belonging to the public network in the city of Vitória, the capital of the State of Espirito Santo. Its aim is to map teachers' experiences of pleasure and suffering, and principally the strategies which they create to defend themselves from the harmful elements of the work environment and to produce health. It affirms the indissolubility between modes of work and modes of subjectivising and notes that the deterioration of the public system of education has produced its effects on the work of teachers, endangering their health and causing, frequently, their absence from their functions due to medical leave or even the abandoning of the profession. It seeks to give visibility to actions which suggest the need to recreate work even within adverse conditions.

Key words: production of subjectivity; prescribed and real work; health and illness

En los hilos de Ariadna: cartografía de la relación salud-trabajo en una escuela pública de Vitória-ES Se trata del estudio cualitativo abordando las relaciones entre salud y trabajo de los profesores de una escuela pública en la ciudad de Vitória, capital del estado de Espíritu Santo. Su objetivo fue cartografiar las vivencias de placer y sufrimiento de los docentes, principalmente las estrategias creadas para defenderse de las nocividades del ambiente de trabajo y producir salud. Afirma la insociabilidad entre modos de trabajar y modos de subjetivar, y constata que la deteriorización del sistema público de 
enseñanza ha producido sus efectos en el trabajo del profesorado, comprometiendo la salud de esos profesionales y causando, muchas veces, su alejamiento de las funciones por medio de licencias médicas o mismo abandono de la profesión. Busca dar visibilidades a las acciones que apuntan para la recreación del trabajo, mismo dentro de condiciones adversas.

Palabras claves: producción de subjetividad; trabajo prescripto y real; salud y enfermedad 